\title{
Commentary: Left ventricular assist devices, they are a-changin'...
}

\author{
Daniel J. Goldstein, MD
}

\footnotetext{
From the Department of Cardiothoracic Surgery, Montefiore Medical Center, Albert Einstein College of Medicine, Bronx, NY.

Disclosures: Educator and Surgical Proctor, Abbott Inc (paid); National Principal Investigator, MOMENTUM 3 Clinical Trial (unpaid).

Received for publication Oct 6, 2019; revisions received Oct 6, 2019; accepted for publication Oct 7, 2019; available ahead of print Oct 24, 2019.

Address for reprints: Daniel J. Goldstein, MD, Department of Cardiothoracic Surgery, Montefiore Medical Center, Albert Einstein College of Medicine, 3400 Bainbridge Ave, MAP Building, 5th Fl, Bronx, NY 10467 (E-mail: dgoldste@montefiore.org).

J Thorac Cardiovasc Surg 2020;160:141-2

$0022-5223 / \$ 36.00$

Copyright (C) 2019 by The American Association for Thoracic Surgery

https://doi.org/10.1016/j.jtcvs.2019.10.041
}

The transition from pulsatile left ventricular assist device technology to miniaturized continuous-flow pumps that transpired more than a decade ago brought indubitable benefits in survival and quality of life. The small size of these pumps expanded their applicability and facilitated surgical implantation, thereby reducing the morbidity of the operation itself. Moreover, their enhanced reliability - a result of the single moving part design-provided longer durations of support and lower rates of device malfunction. Nonetheless, unforeseen clinical challenges, partly engendered by non-physiologic pulseless blood flow, including angiodysplastic mucosal bleeding, de novo aortic insufficiency, and pump thrombosis, have dampened overall success. And although reoperation rates for primary pump failure have largely evaporated, surgeons are still called on to exchange continuous-flow pumps because of infection, malfunction, and thrombosis.

Barac and colleagues ${ }^{1}$ describe the largest available experience with replacement of the 2 durable rotary pumps that have dominated clinical use until recently, namely, the HeartMate II (Abbott Inc, Chicago, Ill) and the HVAD (Medtronic Inc, Minneapolis, Minn) devices. The study, which comprised a total of 125 operations in 104 consecutive patients, compared replacement with the newgeneration HeartMate 3 device $(n=19)$ versus replacement to the same or to the other second-generation device $(\mathrm{n}=95)$. The primary endpoint was a composite of survival free from subsequent pump replacement. In both cohorts, the main etiology for replacement of the original device was pump thrombosis.

Patients who underwent replacement to a HM3 device benefitted from improved survival and reduced need for reoperation when compared with those receiving a second HMII or HVAD pump. This advantage, which becomes obvious in the immediate postoperative period, is perhaps devices. pump. attention.

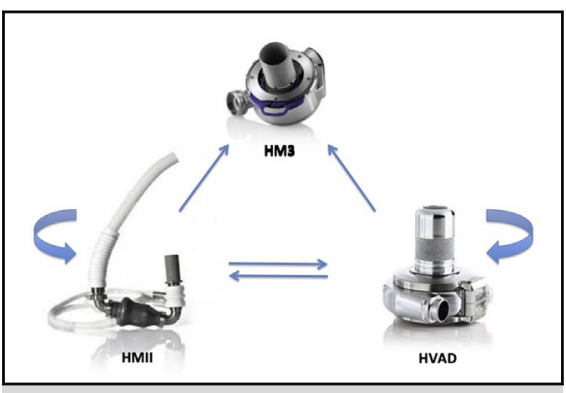

Left ventricular assist device replacement permutations examined in the manuscript.

\section{Central Message}

For patients in need of LVAD pump exchange, replacement with a HM3 device provides survival and freedom from recurrent pump thrombosis benefits.

See Article page 132.

more remarkable given that HM3 recipients had a greater incidence of previous surgeries and underwent redo sternotomy as opposed to the limited surgical approaches used for same-pump replacement of HMII and HVAD

None of the 19 patients who received the HM3 device required yet another operation for pump thrombosis over a mean observation period of 221 days. This salutary benefit parallels that seen for recipients undergoing primary HM3 device implantation in the MOMENTUM 3 (Multicenter Study of MagLev Technology in Patients Undergoing Mechanical Circulatory Support Therapy With HeartMate 3) clinical trial, ${ }^{2}$ an experience that highlighted the favorable hemocompatibility profile of this

The manuscript suffers from its retrospective design, the small and asymmetric composition of the cohorts (19 vs 95), and the fact that it combines into the larger cohort, 4 possible permutations of replacements (HMII to HMII, HMII to HVAD, HVAD to HVAD, and HVAD to HMII). The latter precludes risk adjustment analyses and adds further vagueness to the comparison. Within the context of left ventricular assist device replacement therapies, however, this experience is in fact quite large and deserves

If the long-term (5-year) results of the MOMENTUM 3 clinical trial confirm the hemocompatibility benefits of 
this new technology, and additional experience duplicates the findings by Barac and colleagues, surgical techniques and tools will be developed to standardize and limit the trauma of the replacement operation to a HM3 that could benefit some of the estimated 7600 HMII and 4500 HVAD recipients (Abbott, Inc., and Medtronic, Inc., personal communications, October 2019) currently on support.

\section{References}

1. Barac YD, Wojnarski CM, Junpaparp P, Jawitz OK, Billard H, Daneshmand MA, et al. Early outcomes with durable left ventricular assist device replacement using the HeartMate 3. J Thorac Cardiovasc Surg. 2020;160:132-9.e1.

2. Mehra M, Uriel N, Naka Y, Cleveland JC Jr, Yuzefpolskaya M, Salerno CT, et al. A fully magnetically levitated left ventricular assist device-final report. $N$ Engl $J$ Med. 2019;380:1618-27.

3. Uriel N, Colompo PC, Cleveland JC, Long JW, Salerno C, Goldstein DJ, et al. Hemocompatibility related outcomes at six months in the MOMENTUM 3 shortterm cohort. Circulation. 2017;135:2003-12. 